\title{
Alteration in the intrafollicular thiol-redox system in infertile women with endometriosis
}

\author{
Young Sik Choi ${ }^{1,2}$, SiHyun $\mathrm{Cho}^{2,3}$, Seok Kyo Seo ${ }^{1,2}$, Joo Hyun Park ${ }^{2,3}$, Seok Hyun Kim ${ }^{4}$ and \\ Byung Seok Lee Le,3 $^{2}$ \\ ${ }^{1}$ Department of Obstetrics and Gynecology, Severance Hospital, Yonsei University College of Medicine, \\ Seoul 120-752, Republic of Korea, ${ }^{2}$ Institute of Women's Life Medical Science, Yonsei University College of Medicine, \\ Seoul 120-752, Republic of Korea, ${ }^{3}$ Department of Obstetrics and Gynecology, Gangnam Severance Hospital, \\ Yonsei University College of Medicine, 146-92 Dogok-dong, Kangnam-gu, Seoul 135-720, Republic of Korea and \\ ${ }^{4}$ Department of Obstetrics and Gynecology, College of Medicine, Seoul National University, 28 Yeongeon-Dong, \\ Jongno-Gu, Seoul 110-744, Republic of Korea
}

Correspondence should be addressed to B S Lee; Email: dr222@yuhs.ac or to S H Kim; Email: seokhyun@snu.ac.kr

\begin{abstract}
The aim of this study was to compare intrafollicular biomarkers of thiol-redox system and chronic inflammation in infertile patients with and without endometriosis, and examine correlations between biomarkers and IVF outcomes. The study included 65 patients receiving IVF: 31 patients with endometriosis vs 34 patients without endometriosis. Follicular fluid (FF) was obtained from a single-dominant follicle during oocyte retrieval and stored at $-70^{\circ} \mathrm{C}$. Malondialdehyde, superoxide dismutase, glutathione (GSH), glutathione peroxidase 3 (GPX3), thioredoxin (TRX), TRX-binding protein 2 (TBP2), and peroxiredoxin-4 levels were measured in the FF samples by ELISAs as biomarkers of oxidative stress. The inflammatory cytokines interleukin 1 beta (IL1 $\beta$ ), IL6, IL8, and tumor-necrosis factor alpha $(\mathrm{TNF} \alpha$ ) were also measured by ELISAs. GSH levels were significantly lower in the endometriosis group compared with the controls. TBP2 levels were significantly higher in the endometriosis group. IL6, IL8, and TNF $\alpha$ levels were significantly higher in the endometriosis group. The levels of all of the inflammatory cytokines positively correlated with the levels of TRX. GSH levels positively correlated with the number of high-quality embryos. GPX3 and TRX levels negatively correlated with the percentage of mature oocytes. TNF $\alpha$ levels negatively correlated with the cumulative embryo score per embryo. Logistic regression analysis revealed that the number of high-quality embryos was an independent factor predicting clinical pregnancy. In conclusion, there may be an imbalance in the thiol-redox system and increased levels of inflammatory cytokines in the intrafollicular microenvironment of infertile patients with endometriosis, which may affect the qualities of the oocyte and embryo.

Reproduction (2015) 149 155-162
\end{abstract}

\section{Introduction}

Endometriosis is characterized by the presence of endometrial tissue outside of the uterine cavity and is associated with pain and infertility (Bulun 2009). Approximately $35-50 \%$ of women with infertility have endometriosis (Giudice \& Kao 2004). Similarly, about $30-50 \%$ of patients with endometriosis have impaired fertility (Bulletti et al. 2010). Endometriosis is also associated with a reduced rate of pregnancy after IVF, which may be due to the poor qualities of oocytes and embryos (Garrido et al. 2000).

The mechanisms of endometriosis-associated infertility are not fully understood. However, endometriosis may contribute to infertility by impairing ovarian and tubal function and reducing uterine receptivity (Gupta et al. 2008). Abnormal folliculogenesis, elevated oxidative stress, altered immune function, changes in the hormonal milieu, or decreased endometrial receptivity may also contribute to reduced fertility (Harkki et al. 2010).

Oxidative stress develops due to an imbalance between generation of reactive oxygen species (ROS) and the scavenging capacity of antioxidants in the reproductive tract (Augoulea et al. 2009, Carvalho et al. 2012). An imbalance between ROS production and antioxidant activity causes cellular damage and dysfunction and may affect folliculogenesis. Altered folliculogenesis in patients with endometriosis may contribute to ovulatory dysfunction, poor oocyte quality, reduced fertilization, low-grade embryos, and reduced implantation (Garrido et al. 2003). Changes in the kinetics of granulosa cell cycle may also impair follicular growth and oocyte maturation in patients with endometriosis (Saito et al. 2002). Thus, oxidative stress 
contributes to the infertility associated with endometriosis.

Thiols are organic sulfur derivatives, identified by the presence of sulfhydryl residues (-SH) at their active site. Biological thiols include low-molecular weight free thiols and protein thiols, the functional group of the amino acid cysteine. The thiol-redox system is crucial for the normal function of a specific protein and may affect a vast variety of functions including protein structure, protein-protein interactions, catalysis, electron transfer, ion channel modulation, phosphorylation-dependent signal transduction, post-translational protein modification, and transcriptional activation (Biswas et al. 2006). The extracellular supply of thiols is critical for maintaining the redox state of the extracellular space or microenvironment. Cell-surface and extracellular thiols are important for many cellular functions, including ligand-receptor binding and signal transduction (Chaiswing \& Oberley 2010). The thiol-redox system includes cysteine, glutathione (GSH), thioredoxin (TRX), glutaredoxin, and peroxiredoxin (PRX). GSH is found in various tissues and is expressed in oocytes and embryos. GSH is the substrate of glutathione peroxidase (GPX), which is the main antioxidant enzyme that protects cells from lipid hydroperoxides and $\mathrm{H}_{2} \mathrm{O}_{2}$ (Chaiswing \& Oberley 2010). Thus, GSH represents the main non-enzymatic defense system against ROS. TRX is a redox-regulating antioxidant protein that prevents oxidative stress from damaging cells (Nordberg \& Arner 2001). TRX is considered to be a good marker of oxidative stress. TRX-binding protein 2 (TBP2), which is also known as TRX-interacting protein, vitamin D3-upregulated protein, or TRX-interacting protein, regulates the expression and function of TRX (Nishiyama et al. 1999, Junn et al. 2000). The TRX system regulates the functions of specific genes, coordinates various enzymatic activities, and plays roles in female reproduction and fetal development by regulating cell growth, differentiation, and death (Burton \& Jauniaux 2011). TRX is involved in multiple clinical conditions. TRX alterations have been implicated in cataract formation, ischemic heart disease, cancer, AIDS, rheumatoid arthritis, diabetic complications, and hepatic and renal diseases (Maulik \& Das 2008). The PRX family of antioxidant proteins has been recently discovered and is ubiquitously synthesized and abundantly expressed in various organisms (Rhee et al. 2005). The PRX family includes at least six distinct mammalian $P R X$ genes. The functional activities of PRX proteins depend on reduced forms of TRX and/or GSH (Kang et al. 2005, Rhee et al. 2005). In contrast to the intracellular localization of other family members, PRX4 is the only known secretory form (Jin et al. 1997, Giguere et al. 2007). PRX4 protects against oxidative damage by scavenging ROS in the extracellular space (Jin et al. 1997, Matsumoto et al. 1999).

Endometriosis is associated with inflammatory changes in the intrafollicular microenvironment.
ROS-induced damage can occur through altered expression of cytokines or pro-inflammatory substrates via activation of the redox-sensitive transcription factors AP1, p53, and nuclear factor (NF)-kappa B (Agarwal et al. 2012). Many pro-inflammatory cytokines increase the levels of ROS, which induces oxidative modification of cellular macromolecules through a process called oxidative stress (Schleicher \& Friess 2007). The levels of inflammatory cytokines, such as interleukin 6 (IL6), IL1 $\beta$, and tumor necrosis factor alpha (TNF $\alpha$ ), are increased in the follicular fluid (FF) of patients with endometriosis (Pellicer et al. 1998, Garrido et al. 2000, Wunder et al. 2006). These inflammatory cytokines can activate apoptosis.

There have been several studies focused on ROS and antioxidants in the intrafollicular microenvironment (Oyawoye et al. 2003, Agarwal et al. 2005, Prieto et al. 2012, Singh et al. 2013). However, there have been few reports on the thiol-redox system in the intrafollicular microenvironment of infertile patients with endometriosis (Ebisch et al. 2006, Singh et al. 2013). In addition, although both oxidative stress and chronic inflammation are recognized features of endometriosis, there are few reports investigating the biomarkers of oxidative stress and chronic inflammation in the FF of patients with endometriosis.

The aim of this study was to compare thiol-redox and chronic inflammatory biomarker concentrations in FF samples obtained from infertile patients with and without endometriosis, who were receiving IVF. We also investigated correlations between biomarker concentrations and IVF outcome.

\section{Subjects and methods}

\section{Patients and controls}

Among candidates undergoing controlled ovarian stimulation (COS) for IVF and embryo transfer (IVF-ET) from June 2010 to April 2013, only those aged 30-39 years with a BMI of $16-29 \mathrm{~kg} / \mathrm{m}^{2}$ were included in this study. The following exclusion criteria were adopted: polycystic ovary syndrome, cycles with dominant FF contaminated blood during oocyte retrieval, cycles with dominant FF not yielding oocytes, and the presence of only one ovary. Sixty-five patients receiving IVF were included in this prospective observational study. The endometriosis group consisted of 31 patients with infertility due to endometriosis, which was diagnosed by ultrasound or laparoscopy. Among these patients, 20 patients were surgically treated for the endometriosis before the enrollment. Ultrasound scanning revealed recurrent ovarian endometrioma in 14 patients and six patients had not. Eleven patients were diagnosed with ovarian endometrioma by ultrasound. Thirtyfour patients with unexplained infertility $(n=22)$ or infertility due to male $(n=7)$ or tubal factors $(n=5)$ served as controls.

This study was approved by the institutional review board of the Severance Hospital. Informed consent was obtained from each subject. 


\section{Protocols for COS}

In the gonadotropin-releasing hormone agonist (GNRHa) long protocol, administration of the GNRH agonist triptorelin (Decapeptyl, Ferring, Malmö, Sweden) was initiated at $0.1 \mathrm{mg} /$ day in the mid-luteal phase of the previous cycle. After pituitary release of GNRH was downregulated, the triptorelin dose was reduced to $0.05 \mathrm{mg}$ /day and recombinant follicle-stimulating hormone (FSH) (Gonal-F, Serono) and/or human menopausal gonadotropin (hMG; IVF-M, LG Life Science, Seoul, Korea) were administered. The doses were adjusted based on individual responses, until either the leading follicle reached a mean diameter of $18 \mathrm{~mm}$ or two follicles or more reached diameters of $17 \mathrm{~mm}$. In the GNRH antagonist (GNRHant) multiple-dose flexible protocol, recombinant FSH and/or hMG were administered on the third day of the menstrual cycle. The GNRH antagonist cetrorelix (Gonal-F, Serono) was administered daily at a dose of $0.25 \mathrm{mg}$, starting when the leading follicle reached a diameter of $14 \mathrm{~mm}$ until the leading follicle reached a mean diameter of $18 \mathrm{~mm}$, or two follicles or more reached diameters of $17 \mathrm{~mm}$. In both protocols, urinary human chorionic gonadotropin (hCG) (10 000 IU, IVF-C, LG Life Science) or recombinant hCG $(250 \mu \mathrm{g}$, Ovidrel, Serono) was administered $35 \mathrm{~h}$ before transvaginal oocyte retrieval. Up to four embryos were transferred 2 or 3 days after oocyte retrieval. The embryos were graded according to their morphologies and cleavage rates. On the day of embryo transfer, the grade of each embryo transferred was multiplied by the number of blastomeres to produce a score for each embryo, and the summation of the scores obtained for all the embryos transferred was defined as the cumulative embryo score (CES; Steer et al. 1992). We defined high-quality embryos as those with morphologic grades of I/V or II/ $\mathrm{V}$ and four or five blastomeres on day 2 , and at least seven blastomeres on day 3 after fertilization. The luteal phase was supported with $50 \mathrm{mg}$ progesterone in oil, $8 \%$ progesterone gel (Crinone, Serono) daily, or $800 \mathrm{mg}$ micronized progesterone (Utrogestan, Laboratoires Besins International, Paris, France). Progesterone support was initiated on the day of oocyte retrieval for 14 days and was continued for another 6-8 weeks if a pregnancy was achieved. A clinical pregnancy was identified 4-5 weeks after oocyte retrieval by the presence of an intrauterine gestational sac and a pulsating fetal heartbeat.

\section{FF collection and laboratory assay}

FF was obtained from a single-dominant follicle which had the largest diameter during oocyte retrieval. FF was centrifuged at $250 \boldsymbol{g}$ for $15 \mathrm{~min}$ to separate cellular content and debris. The FF supernatant was transferred to sterile polypropylene tubes and stored at $-70{ }^{\circ} \mathrm{C}$ until assayed. FF samples that were contaminated with blood were excluded. Superoxide dismutase (SOD), GSH, GPX3, TRX, TBP2, and PRX4 (Wuhan EIAAB Science Co., Ltd, Wuhan, China for SOD, GPX3, TRX, TBP2, and PRX4; USCN Life Science, Inc., Wuhan, China for $\mathrm{GSH}$ ) were measured by ELISAs as antioxidant biomarkers. In addition, malondialdehyde (MDA), an indicator of lipid peroxidation, was also measured by ELISA (Wuhan EIAAB
Science Co., Ltd). The inflammatory cytokines IL1 $\beta$, IL6, IL8, and TNF $\alpha$ (R\&D Systems, MN, USA) were also measured by ELISAs. The intra- and inter-assay coefficients of variation were $<10 \%$ in all of the assays.

\section{Statistical analysis}

The sample size was calculated to compare differences between TRX and TBP2 levels in the FF samples. As there has been no report on the intrafollicular levels of these markers, serum levels of these markers from our previous report were used to perform power analysis (Seo et al. 2010). Power analysis showed that at least 31 patients were needed in each group to achieve $80 \%$ power at a $5 \%$ significance level with a two-sided equivalence test if a $30 \%$ difference in mean value was significant.

Data were analyzed with SPSS version 18.0 (SPSS, Inc.). The results were compared between the two groups and statistically analyzed using a Student's $t$-test or $\chi^{2}$ test. When normality of distribution was assessed by means of the test of ShapiroWilks, skewed variables were analyzed by Mann-Whitney $U$ test. Pearson's bivariate correlation coefficient analysis was performed to detect correlations. Multivariate logistic regression analysis was performed to identify factors predicting a clinical pregnancy. The model included potential confounders that were found to be $P<0.1$ in univariate analysis and those that were generally considered to be clinically significant among the various cycle parameters and biomarkers that were assayed. $P<0.05$ was considered statistically significant.

\section{Results \\ Clinical characteristics of study subjects}

There were no significant differences in age, duration of infertility, and basal serum FSH levels. BMI, serum anti-Müllerian hormone $(\mathrm{AMH})$ levels, and total antral follicle counts were significantly lower in the endometriosis group than those in the control group $(20.18 \pm$ 2.16 vs $21.49 \pm 2.76 \mathrm{~kg} / \mathrm{m}^{2}, P=0.039 ; 1.57 \pm 0.75 \mathrm{vs}$ $4.36 \pm 3.91 \mathrm{ng} / \mathrm{ml}, \quad P=0.001 ; 6.90 \pm 3.66$ vs $12.39 \pm$ 6.10, $P<0.001$ ) (Table 1).

\section{Outcomes of COS and IVF-ET}

The duration of stimulation was significantly longer $(11.19 \pm 3.01$ vs $9.11 \pm 1.47$ days, $P=0.001)$, and the total dose of gonadotropin $(3796.77 \pm 1314.36$ vs $1984.03 \pm 1224.51 \mathrm{IU}, P=0.001)$ was significantly higher in the endometriosis group compared with those in the control group. Serum $E_{2}$ levels (1585.8 $\pm 1162.0 \mathrm{vs}$ $3104.97 \pm 2041.8 \mathrm{pg} / \mathrm{ml}, \quad P=0.001)$, the number of follicles $\geq 11 \mathrm{~mm}$ on the day of hCG administration $(6.03 \pm 3.18$ vs $11.35 \pm 7.73, P=0.001)$, and the number of oocytes retrieved $(5.71 \pm 4.58$ vs $12.12 \pm 8.00$, $P<0.001)$ were significantly lower in the endometriosis group compared with those in the control group. Other outcomes, such as number of embryos transferred, CESs 
Table 1 Clinical characteristics and cycle outcomes between the two groups.

\begin{tabular}{|c|c|c|c|}
\hline & $\begin{array}{c}\text { Endometriosis } \\
\quad(n=31)\end{array}$ & $\begin{array}{c}\text { Controls } \\
(n=34)\end{array}$ & $P$ value \\
\hline Age (years) & $34.71 \pm 3.22$ & $35.50 \pm 3.57$ & 0.354 \\
\hline $\mathrm{BMI}\left(\mathrm{kg} / \mathrm{m}^{2}\right)$ & $20.18 \pm 2.16$ & $21.49 \pm 2.76$ & 0.039 \\
\hline $\begin{array}{l}\text { Duration of infertility } \\
\text { (months) }\end{array}$ & $37.42 \pm 27.25$ & $40.50 \pm 22.68$ & 0.627 \\
\hline $\begin{array}{l}\text { Basal serum FSH } \\
\quad(\mathrm{mlU} / \mathrm{ml})\end{array}$ & $11.20 \pm 4.54$ & $9.34 \pm 3.49$ & 0.078 \\
\hline Serum AMH (ng/ml) & $1.57 \pm 0.75$ & $4.36 \pm 3.91$ & 0.00 \\
\hline $\begin{array}{l}\text { Total antral follicle } \\
\text { count }\end{array}$ & $6.90 \pm 3.66$ & $12.39 \pm 6.10$ & $<0.001$ \\
\hline $\begin{array}{l}\text { Duration of COS } \\
\text { (days) }\end{array}$ & $11.19 \pm 3.01$ & $9.11 \pm 1.47$ & 0.001 \\
\hline $\begin{array}{l}\text { Dose of gonado- } \\
\text { tropins used (IU) }\end{array}$ & $\begin{array}{r}3796.77 \pm \\
1314.36\end{array}$ & $\begin{array}{r}1984.03 \pm \\
1224.51\end{array}$ & 0.00 \\
\hline $\begin{array}{l}\text { Serum } E_{2} \text { on hCG day } \\
\quad(\mathrm{pg} / \mathrm{ml})\end{array}$ & $\begin{array}{r}1585.8 \pm \\
1162.0\end{array}$ & $\begin{array}{r}3104.97 \pm \\
2041.8\end{array}$ & 0.001 \\
\hline $\begin{array}{l}\text { No. of oocytes } \\
\text { retrieved }\end{array}$ & $5.71 \pm 4.58$ & $12.12 \pm 8.00$ & $<0.001$ \\
\hline $\begin{array}{l}\text { No. of transferred } \\
\text { embryos }\end{array}$ & $2.42 \pm 1.07$ & $2.50 \pm 0.93$ & 0.77 \\
\hline $\begin{array}{l}\text { Cumulative embryo } \\
\text { scores per embryo } \\
\text { transferred }\end{array}$ & $24.23 \pm 14.69$ & $29.64 \pm 7.66$ & 0.073 \\
\hline $\begin{array}{l}\text { No. of high-quality } \\
\text { embryos }\end{array}$ & $1.39 \pm 1.01$ & $1.65 \pm 1.18$ & 0.381 \\
\hline Fertilization rate (\%) & $107 / 177(60.5)$ & $232 / 412(56.3)$ & 0.365 \\
\hline $\begin{array}{l}\text { Clinical pregnancy } \\
\text { rate per cycle }(\%)\end{array}$ & 11/31 (35.5) & $11 / 34(32.4)$ & 0.7 \\
\hline Implantation rate $(\%)$ & $17 / 63(26.98)$ & $14 / 85(16.47)$ & 0.15 \\
\hline
\end{tabular}

$\mathrm{LH}$, luteinizing hormone; $\mathrm{FSH}$, follicle-stimulating hormone; $\mathrm{AMH}$, anti-Müllerian hormone; COS, controlled ovarian stimulation; IVF-ET, IVF and embryo transfer. Mean \pm s.D.

per embryo, number of high-quality embryos, fertilization rate, implantation rate, and clinical pregnancy rate, did not differ between groups (Table 1).

\section{FF concentrations of inflammatory cytokines and oxidative stress biomarkers}

The levels of IL6, IL8, and TNF $\alpha$ were significantly higher in the FF samples from the endometriosis group compared with those from the control group (16.97 \pm 29.62 vs $4.11 \pm 2.89 \mathrm{pg} / \mathrm{ml}, P=0.022 ; 216.26 \pm 95.73$ vs $171.50 \pm 72.06 \mathrm{pg} / \mathrm{ml}, P=0.037 ; 0.93 \pm 1.01$ vs $0.43 \pm 0.33 \mathrm{pg} / \mathrm{ml}, P=0.036$, respectively). IL $1 \beta$ levels were higher in the FF samples from the endometriosis group compared with those from the control group, but the difference was not significant (Fig. 1).

GSH levels were significantly lower in the FF samples from the endometriosis group than those in the control group $(12.73 \pm 5.67$ vs $16.19 \pm 6.94 \mu \mathrm{g} / \mathrm{ml}, P=0.033)$. Similarly, the levels of TBP2 were significantly higher in the FF samples from the endometriosis group compared with those of the control group $(219.97 \pm 507.23$ vs $3.27 \pm 6.14 \mathrm{ng} / \mathrm{ml}, P=0.042)$. MDA, SOD, GPX3, TRX, and PRX4 levels were not significantly different between groups (Fig. 1).

\section{Relationship between inflammatory cytokines and biomarkers of oxidative stress in FF}

FF levels of IL6, IL8, and TNF $\alpha$ were positively correlated with the FF levels of TRX $(r=0.280, P=0.032 ; r=0.285$, $P=0.029 ; r=0.327, P=0.045$ respectively). Although it was not statistically significant, there was also a positive correlation between FF levels of IL1 $\beta$ and TRX ( $r=0.248$, $P=0.058)(r=0.248, P=0.058)($ Table 2$)$.

\section{Relationship between biomarkers of oxidative stress and chronic inflammation in FF and IVF outcomes}

FF GSH levels were positively correlated with the number of high-quality embryos $(r=0.299, P=0.024)$ but not with the percentage of mature oocytes, fertilization rate, or CES per embryo. The levels of GPX3 and TRX in the FF samples negatively correlated with the percentage of mature oocytes $(r=0.275$, $P=0.046 ; r=0.398, P=0.004$ respectively). TRX levels negatively correlated with the CES per embryo with a borderline significance $(r=-0.261, P=0.062)$. The levels of TNF $\alpha$ in the FF negatively correlated with the CES per embryo $(r=0.278, P=0.025)$ and the number of high-quality embryos $(r=-0.209, P=0.096)$. Other oxidative stress biomarkers and inflammatory cytokines did not correlate with cycle parameters (Table 3).

\section{Predictive factors for a clinical pregnancy}

Univariate logistic regression analysis suggested that a successful clinical pregnancy was influenced by the serum $E_{2}$ levels on the day of hCG administration, the number of high-quality embryos, and the level of GSH in the FF. Multivariate logistic regression analysis revealed that the number of high-quality embryos was an independent predictive factor for clinical pregnancy (OR 0.975, $P=0.024$ ) (Table 4).

\section{Discussion}

In this study, there were significant differences in the FF levels of GSH and TBP2 between the endometriosis and control groups. The FF GSH levels significantly and positively correlated with the quality of the embryo. The concentrations of inflammatory cytokines in the FF significantly and positively correlated with the TRX concentrations in the FF. Furthermore, the levels of inflammatory cytokines were found to be significantly elevated in the FF samples obtained from patients with endometriosis. In addition, TRX concentrations in the FF samples negatively correlated with oocyte maturity and embryo quality. This is the first in vivo study to investigate the integrated effects of thiol-redox and inflammatory factors in the FF of women with endometriosis on IVF outcomes. 

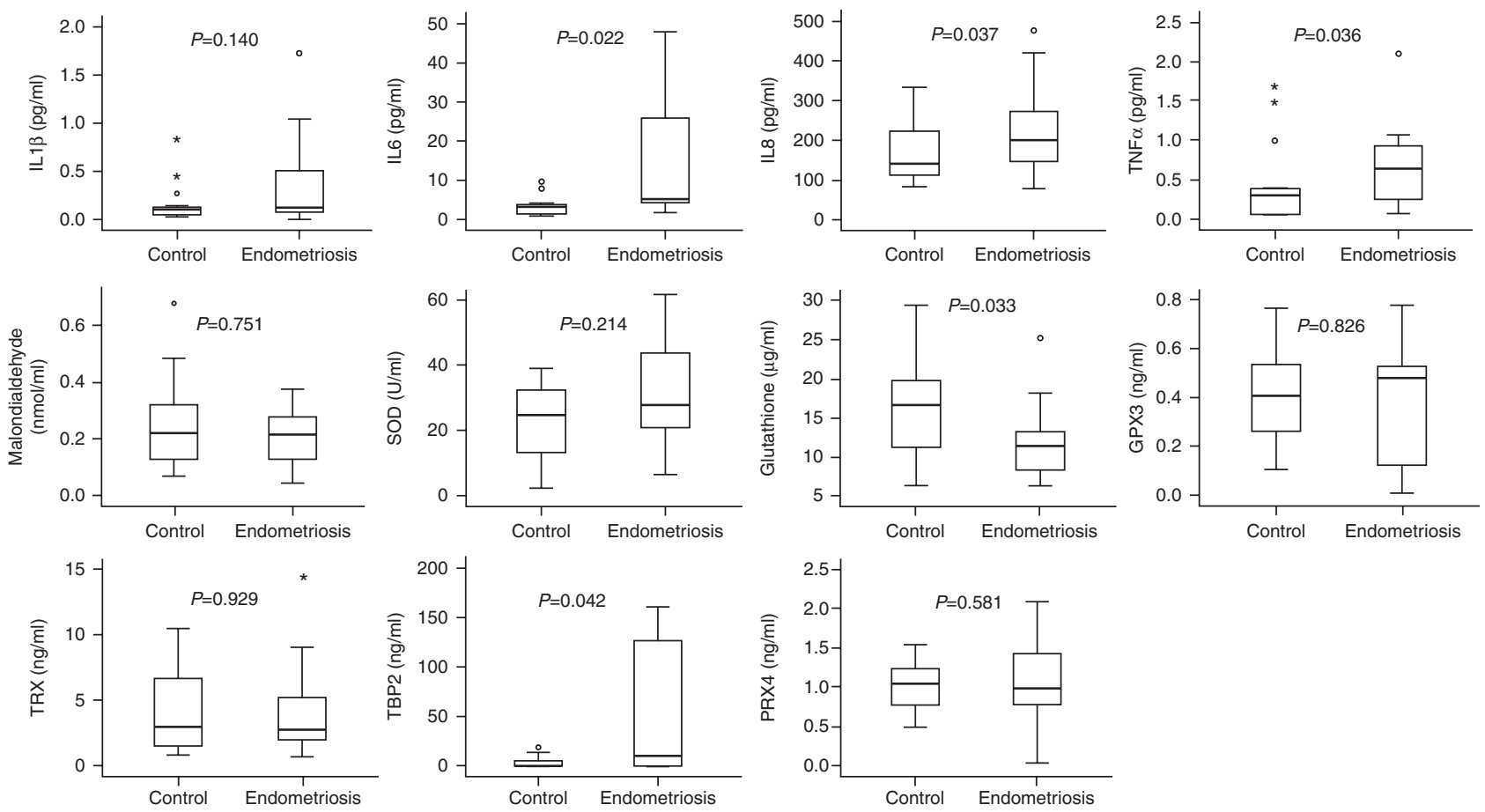

Figure 1 Follicular fluid (FF) concentrations of biomarkers of oxidative stress and chronic inflammation between the two groups. Boxes represent the 25th and 75th percentiles, and the bottom and top whiskers are defined by the 25th percentile minus 1.5 times the interquartile range (IQR) and the 75th percentile plus 1.5 times the IQR respectively. Data points outside this range are plotted as individual points using asterisk and open circle. IL, interleukin; TNF, tumor necrosis factor; SOD, superoxide dismutase; GPX, glutathione peroxidase; TRX, thioredoxin; TBP, TRX-binding protein; PRX, peroxiredoxin.

GSH has been shown to be present in secretions from the female reproductive tract. GSH protects preimplantation embryos from the adverse effects of intracellular GSH depletion (Gardiner et al. 1998). Glutathione plays important roles during maturation and post-fertilization processes in bovine oocytes (Hashimoto et al. 2000). The secreted GSH protects oocytes against excessive levels of ROS during ovulation, helping to ensure successful fertilization. In our study, the levels of GSH in the FF samples from the endometriosis group were significantly lower than those from the control group. In addition, GSH levels were shown to be significantly and negatively correlated with the number of high-quality embryos. Therefore, depletion of GSH from the FF may adversely affect the quality of embryos in women with endometriosis. In contrast, one study reported that there were no differences in GSH levels in the FF from women with endometriosis-related infertility and those from women with infertility due to tubal factors or unexplained infertility (Ebisch et al. 2006). However, because GSH levels were measured from pooled samples of FF from different follicles, this previous study may not accurately reflect the microenvironment of the dominant follicle.

This study showed that GPX3 concentrations in FF samples were negatively correlated with oocyte maturity. GPX3 may indicate a hypoxic environment. Microarray analysis previously revealed that GPX3 gene

Table 2 Pearson's correlation coefficients between inflammatory cytokines and biomarkers of oxidative stress in the FF of study subjects.

\begin{tabular}{|c|c|c|c|c|c|c|c|c|}
\hline & \multicolumn{2}{|c|}{ IL1及 } & \multicolumn{2}{|c|}{ IL6 } & \multicolumn{2}{|c|}{ IL8 } & \multicolumn{2}{|c|}{ TNF $\alpha$} \\
\hline & $r$ & $P$ & $r$ & $P$ & $r$ & $P$ & $r$ & $P$ \\
\hline MDA & -0.143 & 0.232 & -0.111 & 0.352 & -0.166 & 0.167 & -0.140 & 0.329 \\
\hline SOD & -0.156 & 0.188 & -0.053 & 0.658 & -0.115 & 0.336 & -0.088 & 0.541 \\
\hline GSH & -0.137 & 0.245 & -0.143 & 0.223 & -0.164 & 0.166 & -0.151 & 0.292 \\
\hline GPX3 & -0.041 & 0.755 & -0.058 & 0.659 & -0.023 & 0.864 & -0.051 & 0.759 \\
\hline TRX & 0.248 & 0.058 & 0.280 & 0.032 & 0.285 & 0.029 & 0.327 & 0.045 \\
\hline TBP2 & -0.097 & 0.488 & -0.037 & 0.791 & -0.009 & 0.950 & -0.051 & 0.759 \\
\hline PRX4 & 0.034 & 0.774 & 0.024 & 0.838 & 0.029 & 0.807 & -0.040 & 0.781 \\
\hline
\end{tabular}

FF, follicular fluid; IL, interleukin; TNF, tumor necrosis factor; MDA, malondialdehyde; SOD, superoxide dismutase; GSH, glutathione; GPX, glutathione peroxidase; TRX, thioredoxin; TBP, TRX-binding protein; PRX, peroxiredoxin. 
Table 3 Pearson's correlation coefficients between biomarkers of oxidative stress and chronic inflammation in FF and IVF outcomes.

\begin{tabular}{|c|c|c|c|c|c|c|c|c|}
\hline & \multicolumn{2}{|c|}{$\begin{array}{c}\text { No. of mature oocytes/no. of } \\
\text { total oocytes }(\%)\end{array}$} & \multicolumn{2}{|c|}{ Fertilization rate $(\%)$} & \multicolumn{2}{|c|}{$\begin{array}{l}\text { CES/the no. of embryos } \\
\text { trasnferred }\end{array}$} & \multicolumn{2}{|c|}{ No. of high-quality embryos } \\
\hline & $r$ & $P$ & $r$ & $P$ & $r$ & $P$ & $r$ & $P$ \\
\hline MDA & -0.069 & 0.592 & -0.001 & 0.991 & -0.095 & 0.450 & 0.090 & 0.477 \\
\hline SOD & -0.164 & 0.199 & 0.048 & 0.715 & -0.009 & 0.942 & 0.130 & 0.307 \\
\hline $\mathrm{GSH}$ & 0.111 & 0.381 & 0.040 & 0.760 & 0.131 & 0.299 & 0.299 & 0.015 \\
\hline GPX3 & -0.275 & 0.046 & -0.198 & 0.164 & 0.049 & 0.724 & -0.159 & 0.250 \\
\hline TRX & -0.398 & 0.004 & 0.019 & 0.896 & -0.261 & 0.062 & -0.170 & 0.228 \\
\hline TBP2 & 0.018 & 0.905 & 0.072 & 0.640 & -0.179 & 0.224 & -0.112 & 0.448 \\
\hline PRX4 & 0.045 & 0.726 & 0.068 & 0.601 & -0.018 & 0.886 & 0.030 & 0.812 \\
\hline IL1 $\beta$ & 0.114 & 0.372 & 0.042 & 0.748 & -0.096 & 0.450 & -0.026 & 0.838 \\
\hline IL6 & -0.013 & 0.920 & 0.072 & 0.578 & -0.127 & 0.314 & -0.029 & 0.821 \\
\hline IL8 & 0.057 & 0.657 & 0.006 & 0.961 & 0.021 & 0.868 & -0.037 & 0.771 \\
\hline $\mathrm{TNF} \alpha$ & -0.028 & 0.826 & 0.013 & 0.921 & -0.278 & 0.025 & -0.209 & 0.096 \\
\hline
\end{tabular}

FF, follicular fluid; IL, interleukin; TNF, tumor necrosis factor; MDA, malondialdehyde; SOD, superoxide dismutase; GSH, glutathione; GPX, glutathione peroxidase; TRX, thioredoxin; TBP, TRX-binding protein; PRX, peroxiredoxin.

expression was reduced in cumulus cells from oocytes that did not yield early-cleavage embryos (van Montfoort et al. 2008). Hypoxia produces ROS, which cause lipid peroxidation, enzymatic inactivation, and cell damage, resulting in apoptosis (Buttke \& Sandstrom 1994) of cumulus cells and oocytes (Tatemoto et al. 2000). Hypoxia (Van Blerkom et al. 1997) and elevated concentrations of ROS in FF are negatively associated with embryonic development and pregnancy outcome (Pasqualotto et al. 2004, Das et al. 2006) and associated with a significantly higher incidence of aneuploidy and spindle defects in oocytes (Van Blerkom et al. 1997). Among women who are receiving IVF, the mean GPX activity is greater in follicles that yield oocytes that are subsequently fertilized compared with that in follicles with non-fertilized oocytes (Paszkowski et al. 1995). However, this study did not show a correlation between levels of GPX3 in FF samples and fertilization rate.

Endometriosis is associated with inflammatory changes in the FF. This study showed that the levels of IL6, IL8, and TNF $\alpha$ were significantly higher in the FF of women with endometriosis compared with those in the controls, which was consistent with previous studies (Pellicer et al. 1998, Garrido et al. 2000, Wunder et al. 2006). The pro-inflammatory intrafollicular microenvironment in women with endometriosis may influence the qualities of oocytes and embryos. In this study, the levels of TNF $\alpha$ in FF samples negatively correlated with the quality of embryos. TNF $\alpha$ in FF has been proposed to be related with oocyte quality and IVF outcomes (Lee et al.
2000), which is consistent with our results. Previous work suggested that elevated levels of IL6 in FF may be detrimental to implantation (Altun et al. 2011). However, we did not observe this relationship in our study. Consistent with other reports (Gazvani et al. 2000, Hammadeh et al. 2002, 2003), we did not find a correlation between IL8 concentrations and IVF outcomes.

Although TRX levels in FF did not differ between groups, TBP2 levels were significantly higher in the FF samples from the endometriosis group compared with those from the control group. The levels of TRX and TBP2 in serum and peritoneal fluid samples from patients with endometriosis were previously reported to be similar to controls (Lambrinoudaki et al. 2009, Seo et al. 2010). These findings may be due to differences between the systemic environment and the local intrafollicular environment. TBP2 was originally identified as a negative regulator of TRX and acts as a suppressor of cell growth and regulator of lipid/glucose metabolism (Watanabe et al. 2010). In addition, TBP2 may enhance the atherosclerotic process by increasing vascular inflammation (World et al. 2006). Our study showed that the levels of TRX in FF were positively correlated with the levels of IL1 $\beta$, IL6, IL8, and TNF $\alpha$ in FF. Therefore, we hypothesize that oxidative damage activates the TRX system as a protective mechanism, which activates inflammatory cytokines in the intrafollicular microenvironment. In addition, TRX levels were negatively correlated with oocyte maturation and

Table 4 Logistic regression analysis of predictive factors for a clinical pregnancy.

\begin{tabular}{|c|c|c|c|c|}
\hline \multirow[b]{2}{*}{ Variables } & \multicolumn{2}{|c|}{ Univariate } & \multicolumn{2}{|c|}{ Multivariate } \\
\hline & OR $(95 \% \mathrm{Cl})$ & $P$ value & OR $(95 \% \mathrm{Cl})$ & $P$ value \\
\hline Basal serum FSH & $0.867(0.739-1.017)$ & 0.080 & - & - \\
\hline Total antral follicle count & $1.091(0.993-1.200)$ & 0.069 & - & - \\
\hline Serum $\mathrm{E}_{2}$ levels on hCG day & $1.000(1.000-1.001)$ & 0.033 & $1.000(1.000-1.001)$ & 0.174 \\
\hline No. of high-quality embryos & $1.983(1.168-3.365)$ & 0.011 & $1.904(1.085-3.341)$ & 0.025 \\
\hline $\mathrm{FF} \mathrm{GSH}$ & $1.089(1.002-1.184)$ & 0.044 & $1.044(0.951-1.146)$ & 0.364 \\
\hline
\end{tabular}

FSH, follicle-stimulating hormone; $\mathrm{E}_{2}$, estradiol; hCG, human chorionic gonadotropin; FF, follicular fluid; GSH, glutathione. 
embryo quality, and TNF $\alpha$ levels were negatively correlated with embryo quality. Thus, excessive oxidative stress and inflammatory changes in the intrafollicular microenvironment may affect the qualities of the oocyte and embryo.

Although GSH, GPX3, TRX, and TNF $\alpha$ levels were significantly correlated with IVF outcomes, multivariate logistic regression analysis revealed that the number of high-quality embryos was significantly and independently correlated with clinical pregnancy. Thus, the thiol-redox system and inflammatory cytokines might be involved in the achievement of a clinical pregnancy due to their impact on the qualities of the oocyte and embryo.

There are several limitations to our study. Firstly, because diagnostic laparoscopy was not routinely performed in our hospital, we cannot rule out the existence of minimal and mild endometriosis in the control group. However, careful imaging has demonstrated to be sensitive enough to detect small cysts or firm adhesions (Garcia-Velasco et al. 2010). Secondly, although we are concerned about microenvironment of dominant follicle, which is most likely to contain a mature oocyte, results of FF samples from a singledominant follicle may not reflect the other follicles in the ovary. In this study, thirdly, there was a significant difference in ovarian reserve and the number of oocytes retrieved between patients with and without endometriosis. These differences may be due to the surgery and/ or endometriosis itself in patients with endometriosis. However, markers of ovarian reserve and the number of oocytes retrieved were not correlated with biomarkers of oxidative stress and chronic inflammation. Therefore, differences in ovarian reserve may not affect the results of this study.

In conclusion, alterations in the thiol-redox system and increased levels of inflammatory cytokines were found in the intrafollicular microenvironment of infertile patients with endometriosis who were receiving IVF. These changes may affect the qualities of the oocyte and embryo.

\section{Declaration of interest}

The authors declare that there is no conflict of interest that could be perceived as prejudicing the impartiality of the research reported.

\section{Funding}

This work was supported by the Basic Science Research Program through the National Research Foundation of Korea (NRF) funded by the Ministry of Education, Science and Technology (grant number 2010-0003065) and a grant from the Korea Healthcare Technology R\&D Project, Ministry of Health and Welfare (grant number A120043), Republic of Korea.

\section{References}

Agarwal A, Gupta S \& Sharma R 2005 Oxidative stress and its implications in female infertility - a clinician's perspective. Reproductive Biomedicine Online 11 641-650. (doi:10.1016/S1472-6483(10)61174-1)

Agarwal A, Aponte-Mellado A, Premkumar BJ, Shaman A \& Gupta S 2012 The effects of oxidative stress on female reproduction: a review. Reproductive Biology and Endocrinology 10 49. (doi:10.1186/14777827-10-49)

Altun T, Jindal S, Greenseid K, Shu J \& Pal L 2011 Low follicular fluid IL-6 levels in IVF patients are associated with increased likelihood of clinical pregnancy. Journal of Assisted Reproduction and Genetics 28 245-251. (doi:10.1007/s10815-010-9502-8)

Augoulea A, Mastorakos G, Lambrinoudaki I, Christodoulakos G \& Creatsas G 2009 The role of the oxidative-stress in the endometriosisrelated infertility. Gynecological Endocrinology 25 75-81. (doi:10.1080/ 09513590802485012)

Biswas S, Chida AS \& Rahman I 2006 Redox modifications of protein-thiols: emerging roles in cell signaling. Biochemical Pharmacology $\mathbf{7 1}$ 551-564. (doi:10.1016/j.bcp.2005.10.044)

Bulletti C, Coccia ME, Battistoni S \& Borini A 2010 Endometriosis and infertility. Journal of Assisted Reproduction and Genetics 27 441-447. (doi:10.1007/s10815-010-9436-1)

Bulun SE 2009 Endometriosis. New England Journal of Medicine $\mathbf{3 6 0}$ 268-279. (doi:10.1056/NEJMra0804690)

Burton GJ \& Jauniaux E 2011 Oxidative stress. Best Practice \& Research. Clinical Obstetrics \& Gynaecology 25 287-299. (doi:10.1016/j. bpobgyn.2010.10.016)

Buttke TM \& Sandstrom PA 1994 Oxidative stress as a mediator of apoptosis. Immunology Today 15 7-10. (doi:10.1016/0167-5699(94)90018-3)

Carvalho LF, Samadder AN, Agarwal A, Fernandes LF \& Abrao MS 2012 Oxidative stress biomarkers in patients with endometriosis: systematic review. Archives of Gynecology and Obstetrics 286 1033-1040. (doi:10. 1007/s00404-012-2439-7)

Chaiswing L \& Oberley TD 2010 Extracellular/microenvironmental redox state. Antioxidants \& Redox Signaling 13 449-465. (doi:10.1089/ars. 2009.3020)

Das S, Chattopadhyay R, Ghosh S, Ghosh S, Goswami SK, Chakravarty BN \& Chaudhury K 2006 Reactive oxygen species level in follicular fluid embryo quality marker in IVF? Human Reproduction 21 2403-2407. (doi:10.1093/humrep/del156)

Ebisch IM, Peters WH, Thomas CM, Wetzels AM, Peer PG \& SteegersTheunissen RP 2006 Homocysteine, glutathione and related thiols affect fertility parameters in the (sub)fertile couple. Human Reproduction 21 1725-1733. (doi:10.1093/humrep/del081)

Garcia-Velasco JA, Cerrillo M \& Ornat L 2010 Ultrasonography of pelvic endometriosis. In Ultrasonography in Reproductive Medicine and Infertility, pp 119-125. Ed. B Rizk. Cambridge: Cambridge University Press.

Gardiner CS, Salmen JJ, Brandt CJ \& Stover SK 1998 Glutathione is present in reproductive tract secretions and improves development of mouse embryos after chemically induced glutathione depletion. Biology of Reproduction 59 431-436. (doi:10.1095/biolreprod59.2.431)

Garrido N, Navarro J, Remohi J, Simon C \& Pellicer A 2000 Follicular hormonal environment and embryo quality in women with endometriosis. Human Reproduction Update 6 67-74. (doi:10.1093/ humupd/6.1.67)

Garrido N, Pellicer A, Remohi J \& Simon C 2003 Uterine and ovarian function in endometriosis. Seminars in Reproductive Medicine 21 183-192. (doi:10.1055/s-2003-41325)

Gazvani MR, Bates M, Vince G, Christmas S, Lewis-Jones DI \& Kingsland C 2000 Follicular fluid concentrations of interleukin-12 and interleukin-8 in IVF cycles. Fertility and Sterility 74 953-958. (doi:10.1016/S00150282(00)01538-7)

Giguere P, Turcotte ME, Hamelin E, Parent A, Brisson J, Laroche G, Labrecque P, Dupuis G \& Parent JL 2007 Peroxiredoxin-4 interacts with and regulates the thromboxane $\mathrm{A}(2)$ receptor. FEBS Letters 581 3863-3868. (doi:10.1016/j.febslet.2007.07.011)

Giudice LC \& Kao LC 2004 Endometriosis. Lancet 364 1789-1799. (doi:10.1016/S0140-6736(04)17403-5)

Gupta S, Goldberg JM, Aziz N, Goldberg E, Krajcir N \& Agarwal A 2008 Pathogenic mechanisms in endometriosis-associated infertility. Fertility and Sterility 90 247-257. (doi:10.1016/j.fertnstert.2008.02.093) 
Hammadeh ME, Ertan AK, Georg MT, Rosenbaum P \& Schmidt W 2002 Relationship between ovarian stimulation regimen and interleukin level in pre-ovulatory follicular fluid and their effect on ICSI outcome. American Journal of Reproductive Immunology 48 255-261. (doi:10.1034/j.1600-0897.2002.01123.x)

Hammadeh ME, Fischer-Hammadeh C, Georg T, Rosenbaum P \& Schmidt W 2003 Comparison between cytokine concentration in follicular fluid of poor and high responder patients and their influence of ICSI-outcome. American Journal of Reproductive Immunology $\mathbf{5 0}$ 131-136. (doi:10.1034/j.1600-0897.2003.00062.x)

Harkki P, Tiitinen A \& Ylikorkala O 2010 Endometriosis and assisted reproduction techniques. Annals of the New York Academy of Sciences 1205 207-213. (doi:10.1111/j.1749-6632.2010.05656.x)

Hashimoto S, Minami N, Yamada M \& Imai H 2000 Excessive concentration of glucose during in vitro maturation impairs the developmental competence of bovine oocytes after in vitro fertilization: relevance to intracellular reactive oxygen species and glutathione contents. Molecular Reproduction and Development 56 520-526. (doi:10.1002/10982795(200008)56:4<520::AID-MRD10>3.0.CO;2-0)

Jin DY, Chae HZ, Rhee SG \& Jeang KT 1997 Regulatory role for a novel human thioredoxin peroxidase in NF- $\mathrm{KB}$ activation. Journal of Biological Chemistry 272 30952-30961. (doi:10.1074/jbc.272.49.30952)

Junn E, Han SH, Im JY, Yang Y, Cho EW, Um HD, Kim DK, Lee KW, Han PL, Rhee SG et al. 2000 Vitamin $D_{3}$ up-regulated protein 1 mediates oxidative stress via suppressing the thioredoxin function. Journal of Immunology 164 6287-6295. (doi:10.4049/jimmunol.164.12.6287)

Kang SW, Rhee SG, Chang TS, Jeong W \& Choi MH 2005 2-Cys peroxiredoxin function in intracellular signal transduction: therapeutic implications. Trends in Molecular Medicine 11 571-578. (doi:10.1016/ j.molmed.2005.10.006)

Lambrinoudaki IV, Augoule A, Christodoulakos GE, Economou EV, Kaparos G, Kontoravdis A, Papadias C \& Creatsas G 2009 Measurable serum markers of oxidative stress response in women with endometriosis. Fertility and Sterility 91 46-50. (doi:10.1016/j.fertnstert.2007.11.021)

Lee KS, Joo BS, Na YJ, Yoon MS, Choi OH \& Kim WW 2000 Relationships between concentrations of tumor necrosis factor- $\alpha$ and nitric oxide in follicular fluid and oocyte quality. Journal of Assisted Reproduction and Genetics 17 222-228. (doi:10.1023/A:1009495913119)

Matsumoto A, Okado A, Fujii T, Fujii J, Egashira M, Niikawa N \& Taniguchi $\mathbf{N} 1999$ Cloning of the peroxiredoxin gene family in rats and characterization of the fourth member. FEBS Letters 443 246-250. (doi:10.1016/S0014-5793(98)01736-0)

Maulik N \& Das DK 2008 Emerging potential of thioredoxin and thioredoxin interacting proteins in various disease conditions. Biochimica et Biophysica Acta 1780 1368-1382. (doi:10.1016/j.bbagen.2007. 12.008)

van Montfoort AP, Geraedts JP, Dumoulin JC, Stassen AP, Evers JL \& Ayoubi TA 2008 Differential gene expression in cumulus cells as a prognostic indicator of embryo viability: a microarray analysis. Molecular Human Reproduction 14 157-168. (doi:10.1093/molehr/gam088)

Nishiyama A, Matsui $M$, Iwata S, Hirota K, Masutani H, Nakamura $H$, Takagi Y, Sono H, Gon Y \& Yodoi J 1999 Identification of thioredoxinbinding protein-2/vitamin $\mathrm{D}(3)$ up-regulated protein 1 as a negative regulator of thioredoxin function and expression. Journal of Biological Chemistry 274 21645-21650. (doi:10.1074/jbc.274.31.21645)

Nordberg J \& Arner ES 2001 Reactive oxygen species, antioxidants, and the mammalian thioredoxin system. Free Radical Biology \& Medicine 31 1287-1312. (doi:10.1016/S0891-5849(01)00724-9)

Oyawoye O, Abdel Gadir A, Garner A, Constantinovici N, Perrett C \& Hardiman P 2003 Antioxidants and reactive oxygen species in follicular fluid of women undergoing IVF: relationship to outcome. Human Reproduction 18 2270-2274. (doi:10.1093/humrep/deg450)
Pasqualotto EB, Agarwal A, Sharma RK, Izzo VM, Pinotti JA, Joshi NJ \& Rose BI 2004 Effect of oxidative stress in follicular fluid on the outcome of assisted reproductive procedures. Fertility and Sterility 81 973-976. (doi:10.1016/j.fertnstert.2003.11.021)

Paszkowski T, Traub Al, Robinson SY \& McMaster D 1995 Selenium dependent glutathione peroxidase activity in human follicular fluid. Clinica Chimica Acta 236 173-180. (doi:10.1016/0009-8981(95)98130-9)

Pellicer A, Albert C, Mercader A, Bonilla-Musoles F, Remohi J \& Simon C 1998 The follicular and endocrine environment in women with endometriosis: local and systemic cytokine production. Fertility and Sterility 70 425-431. (doi:10.1016/S0015-0282(98)00204-0)

Prieto L, Quesada JF, Cambero O, Pacheco A, Pellicer A, Codoceo R \& Garcia-Velasco JA 2012 Analysis of follicular fluid and serum markers of oxidative stress in women with infertility related to endometriosis. Fertility and Sterility 98 126-130. (doi:10.1016/j.fertnstert.2012.03.052)

Rhee SG, Chae HZ \& Kim K 2005 Peroxiredoxins: a historical overview and speculative preview of novel mechanisms and emerging concepts in cell signaling. Free Radical Biology \& Medicine 38 1543-1552. (doi:10. 1016/j.freeradbiomed.2005.02.026)

Saito H, Seino T, Kaneko T, Nakahara K, Toya M \& Kurachi H 2002 Endometriosis and oocyte quality. Gynecologic and Obstetric Investigation 53 (Suppl 1) 46-51. (doi:10.1159/000049424)

Schleicher E \& Friess U 2007 Oxidative stress, AGE, and atherosclerosis. Kidney International. Supplement 72 S17-S26. (doi:10.1038/sj.ki. 5002382)

Seo SK, Yang HI, Lee KE, Kim HY, Cho S, Choi YS \& Lee BS 2010 The roles of thioredoxin and thioredoxin-binding protein-2 in endometriosis. Human Reproduction 25 1251-1258. (doi:10.1093/humrep/deq027)

Singh AK, Chattopadhyay R, Chakravarty B \& Chaudhury K 2013 Markers of oxidative stress in follicular fluid of women with endometriosis and tubal infertility undergoing IVF. Reproductive Toxicology 42 116-124. (doi:10.1016/j.reprotox.2013.08.005)

Steer CV, Mills CL, Tan SL, Campbell S \& Edwards RG 1992 The cumulative embryo score: a predictive embryo scoring technique to select the optimal number of embryos to transfer in an in-vitro fertilization and embryo transfer programme. Human Reproduction 7 117-119.

Tatemoto H, Sakurai N \& Muto N 2000 Protection of porcine oocytes against apoptotic cell death caused by oxidative stress during In vitro maturation: role of cumulus cells. Biology of Reproduction 63 805-810. (doi:10.1095/biolreprod63.3.805)

Van Blerkom J, Antczak M \& Schrader R 1997 The developmental potential of the human oocyte is related to the dissolved oxygen content of follicular fluid: association with vascular endothelial growth factor levels and perifollicular blood flow characteristics. Human Reproduction 12 1047-1055. (doi:10.1093/humrep/12.5.1047)

Watanabe R, Nakamura H, Masutani H \& Yodoi J 2010 Anti-oxidative, anti-cancer and anti-inflammatory actions by thioredoxin 1 and thioredoxin-binding protein-2. Pharmacology \& Therapeutics 127 261-270. (doi:10.1016/j.pharmthera.2010.04.004)

World CJ, Yamawaki H \& Berk BC 2006 Thioredoxin in the cardiovascular system. Journal of Molecular Medicine 84 997-1003. (doi:10.1007/ s00109-006-0109-6)

Wunder DM, Mueller MD, Birkhauser MH \& Bersinger NA 2006 Increased ENA-78 in the follicular fluid of patients with endometriosis. Acta Obstetricia et Gynecologica Scandinavica 85 336-342. (doi:10.1080/ 00016340500501715)

Received 22 August 2014

First decision 6 October 2014

Revised manuscript received 13 October 2014

Accepted 5 November 2014 